\title{
Intestinal Obstruction Due to an Internal Hernia through a Defect of the Broad Ligament in an Adult Female Patient: Case Report and Literature Review
}

\author{
Samuel A. Essoun'1, Samuel Debrah ${ }^{2}$ \\ ${ }^{1}$ Department of Surgery, Central Regional Hospital, Cape Coast, Ghana \\ ${ }^{2}$ Department of Surgery, School of Medical Sciences, University of Cape Coast, Cape Coast, Ghana \\ Email: essoun@gmail.com
}

Received 8 May 2014; revised 2 June 2014; accepted 1 July 2014

Copyright (C) 2014 by authors and Scientific Research Publishing Inc.

This work is licensed under the Creative Commons Attribution International License (CC BY).

http://creativecommons.org/licenses/by/4.0/

(c) (i) Open Access

\begin{abstract}
Internal hernia is a rare cause of intestinal obstruction. We present a case of 43-year-old woman without any prior surgical history who was referred as a case of obstructed para-umbilical hernia from a satellite clinic. The objective is to highlight the occurrence of such a rare clinical problem and to provide an insight into decision making especially when there is discordance between an obvious pathology and clinical features.
\end{abstract}

Keywords

Internal Hernia, Broad Ligament Defect, Intestinal Obstruction

\section{Introduction}

Intestinal obstruction is a very common surgical emergency the world over. However, obstruction due to internal hernia is rare with a frequency reported by many series as less than $1 \%$. Internal hernia is defined generally as the protrusion of an intra-abdominal viscus - in this case the small bowel-through either a recess created by a defect in the mesentery or into the retroperitoneal fossa. Common types of internal hernias include para-duodenal, peri-caecal etc. Herniation through the broad ligament is a rare cause of internal hernia. We present a case of a 43-year-old woman without any prior surgical history who was referred as a case of obstructed para-umbilical hernia from a satellite clinic. The objective is to highlight the occurrence of such a rare clinical problem and to provide an insight into the decision making especially when there is discordance between an obvious pathol- 
ogy and clinical features.

\section{Case Report}

A 43-year-old nulliparous woman with no significant medical or surgical history reported with a 3-day history of colicky abdominal pain, obstipation, a 2-day history of abdominal distension and bilious vomiting. She had no related systemic symptoms and no fever. She had an asymptomatic para-umbilical hernia but she had no recent history of ill health prior to onset of symptoms.

Initial assessment revealed a middle aged woman who was conscious and well oriented. She was neither pale nor jaundiced. She was however mildly dehydrated. Her vital signs at presentation were: HR — 90 bpm, BP130/80, RR -20 cycles/min, and Temp $-36^{\circ} \mathrm{C}$. She had no detectable cardio-respiratory system abnormality.

Abdominal examination revealed a distended abdomen with a reducible para-umbilical hernia. There was tenderness in the peri-umbilical region without any guarding or rebound tenderness. The bowel sounds were frequent and a rectal examination revealed an empty rectum.

She was rehydrated with IV Ringers Lactate, nasogastric decompression done with a Ryles tube and a urethral catheter was inserted. Results of laboratory investigations were as follows:

$\mathrm{Hb}-13.8 \mathrm{~g} / \mathrm{dl}, \mathrm{WBC}-6.8 \times 10^{9} / \mathrm{dl}, \mathrm{Na}^{+}-144 \mathrm{mmol} / \mathrm{l}, \mathrm{K}^{+}-4.7 \mathrm{mmol} / \mathrm{l}$, urea $-24 \mathrm{mg} / \mathrm{ml}$ (15 - 53), creatinine $-0.8 \mathrm{mg} / \mathrm{ml}(0.6$ - 1.1).

Plain abdominal X-rays revealed small bowel dilatation and multiple air-fluid levels leading to a diagnosis of intestinal obstruction. This picture however could not be explained by the para-umbilical hernia. The decision was therefore taken to perform an exploratory laparotomy.

At laparotomy, findings were of multiple right ovarian cysts and a herniation of a $10 \mathrm{~cm}$ ileal segment through a $3 \mathrm{~cm}$ defect in the broad ligament of the right ovary.

The viable bowel was reduced and the defect closed with vicryl 3/0 suture. The broad ligament on the contralateral side was examined and found not to have any defects. No other intra-abdominal or pelvic pathology was found other than the para-umbilical hernia.

The wound closure incorporated the repair of the para-umbilical hernia.

\section{Discussion}

Internal hernia remains a rarity as a cause of intestinal obstruction. The common causes of internal hernia include paraduodenal hernias (53\%), pericaecal (13\%), foramen of Winslow (8\%), transmesenteric (8\%), intersigmoid (6\%) and retro-anastomotic (5\%) [1]. Herniation through defects in the broad ligament forms less than 5\% of all internal hernias [2]. The first case of internal herniation was reported by Quain in 1861 from an autopsy series [3]. Sue Zann Lim et al. reported in a review in 2012 that a total of 28 cases of internal hernia through either a unilateral or bilateral defect in the broad ligament had been reported in the English literature [4].

Broad ligament hernias have two classification systems based on either the degree of peritoneal defect or the location of the defect within the broad ligament.

The first classification by Hunt [5] was based on degree of defect in 1934 as follows: Fenestra type (commonest): defect in the two peritoneal layers which our patient had. Pouch type: a defect in one of the peritoneal layer with viscera trapped within parametrial tissue. Hernia sac type: herniated viscus lined by double leaf of peritoneum forming a true hernia sac which will have to be closed to prevent recurrence.

In 1986, Cilley [6] classified the hernias based on anatomic location of the defects: Type I: defect caudal to the round ligament (commonest). Type II: defect above the broad ligament. Type III: defect between round ligament and the rest of the broad ligament through the meso-ligamentum teres (division of round ligament easily corrects the defect).

Defects in the broad ligament may be either acquired or congenital. Acquired causes may be from trauma from pregnancy or delivery during vaginal manipulations, surgery like repair of obturator hernia, laparoscopic sterilization and electrocoagulation therapy for endometriosis or from pelvic inflammatory disease [7]-[10]. In nulliparous women, spontaneous rupture of cystic structures within the broad ligament thought to be remnants of the mesonephric or Mullerian ducts are implicated [11].

Case reports which have been reviewed reveal that, as was in our case, the most common content of the hernia through the broad ligament is small bowel. However there have been reports of the sigmoid colon, caecum, appendix, ureter and ovaries as content with complications such as bowel ischaemia, ileovaginal fistula, ureteric 
obstruction and ovarian torsion with gangrenous strangulation [12]-[14].

The diagnosis of hernia through the broad ligament is difficult to make preoperatively since an intestinal obstruction generically presents with nonspecific features. Routine upright and supine abdominal X-rays will show the classic features of small bowel obstruction without necessarily pointing to the primary cause of the obstruction in the absence of stigmata such as previous surgery. With recent advances in diagnostic imaging, preoperative CT scan has occasionally yielded a positive finding of a closed loop in small bowel obstruction with the hernia located lateral to the uterus. This was the first description and report by Balthazar et al. [15]. Other features on CT scan include a medial rotation of the involved broad ligament and fallopian tube or a widened distance between the uterus and the ipsilateral ovary [16].

The role of laparoscopy in the diagnosis and intervention has gained widespread recognition and is now the preferred modality in establishing a diagnosis and in the treatment of uncomplicated cases. The defect in the ligament is closed with clips, sutures or the broad ligament is divided. It is essential to examine the ligament on the contralateral side and close any defect if one is present [17].

In resource deprived centres, laparotomy remains the mainstay in the diagnosis and treatment of herniation through defects in the broad ligament. As it was with our patient, the incarcerated small bowel was reduced and the defect closed with vicryl 3.0 suture.

\section{Conclusion}

Even though herniation through a defect in the broad ligament is rare, it is incumbent upon the surgeon to entertain this diagnosis, particularly in a nulliparous female without previous abdominopelvic surgery. Early recognition allows for prompt intervention to avert the potential of strangulation.

\section{References}

[1] Ghahremani, G.G. (1984) Internal Abdominal Hernias. Surgical Clinics of North America, 64, 393-406.

[2] Slezak, F.A. and Schlueter, T.M. (1995) Hernia of the Broad Ligament. Hernia, 4, 491-497.

[3] Quain (1861) Case of Internal Strangulation of a Large Portion of Ileum. Transactions of the Pathological Society of London, 12, 103-104.

[4] Lim, S.Z. (2012) Case Report of an Internal Hernia through a Unilateral Congenital Defect of the Broad Ligament and Literature Review. Proceedings of Singapore Healthcare, 21, 213-216.

[5] Hunt, A.B. (1934) Fenestra and Pouches in the Broad Ligament as an Actual and Potential Cause of Strangulated Intraabdominal Hernia. Surgery, Gynecology, Obstetrics, 58, 906-913.

[6] Cilley, R., Poterack, K., Lemmer, J. and Dafoe, D. (1986) Defects of the Broad Ligament of the Uterus. American Journal of Gastroenterology, 81, 389-391.

[7] Tanaka, M., Kaneko, Y., Letsugu, K. and Yoshida, C. (1994) Internal Herniation through a Broad Ligament Defect after Obturator Hernia Repair. Surgery Today, 24, 634-637. http://dx.doi.org/10.1007/BF01833730

[8] Denton, G.W., Schofield, J.B. and Gallagher, P. (1990) Uncommon Complications of Laparoscopic Sterilisation. Archive of Annals of the Royal College of Surgeons of England, 72, 210-211.

[9] Redwine, D.B. (1989) Symptomatic Internal Hernia of the Therapy of Endometriosis. Obstetrics Gynecology, 73, 495496.

[10] Ishihara, H., Terahara, M., Kigawa, J., et al. (1993) Strangulated Herniation through a Defect in the Broad Ligament of the Uterus. Gynecologic and Obstetric Investigation, 35, 187-189. http://dx.doi.org/10.1159/000292697

[11] Gray, S.W. and Skandalakis, J.E. (1972) Embryology for Surgeons. WA Saunders, Philadelphia.

[12] Demir, H. and Scoccia, B. (2010) Internal Herniation of Adnexa through a Defect of the Broad Ligament: Case Report and Literature Review. Journal of Minimally Invasive Gynecology, 17, 110-112. http://dx.doi.org/10.1016/j.jmig.2009.10.002

[13] Nackley, A.C. and Yeko, T.R. (2000) Ureteral Displacement Associated with Pelvic Peritoneal Defects and Endometriosis. Journal of the American Association of Gynecologic Laparoscopists, 7, 131-133. http://dx.doi.org/10.1016/S1074-3804(00)80023-7

[14] Bates, G.J., Bennett, I.C. and Furnival, C.M. (1983) A Strangulated Hernia through the Broad Ligament Causing Ureteric Obstruction. Journal of the Royal College of Surgeons of Edinburgh, 28, 335.

[15] Balthazar, E.J., Birnbaum, B.A., Megibow, A.J., Gordon, R.B., Whelan, C.A. and Hulnick, D.H. (1992) Closed-Loop and Strangulating Intestinal Obstruction: CT Signs. Radiology, 185, 769-775. 
[16] Barbier Brion, B., Daragon, C., Idelcadi, O., Mantion, G., Kastler, B. and Delabrousse, E. (2011) Small Bowel Obstruction Due to Broad Ligament Hernia: Computer Tomography Findings. Hernia, 15, 353-355. http://dx.doi.org/10.1007/s10029-010-0660-5

[17] Bangari, R. and Uchil, D. (2012) Laparoscopic Management of Internal Hernia of Small Intestine through a Broad Ligament Defect. Journal of Minimally Invasive Gynecology, 19, 122-124. http://dx.doi.org/10.1016/j.jmig.2011.09.001 
Scientific Research Publishing (SCIRP) is one of the largest Open Access journal publishers. It is currently publishing more than 200 open access, online, peer-reviewed journals covering a wide range of academic disciplines. SCIRP serves the worldwide academic communities and contributes to the progress and application of science with its publication.

Other selected journals from SCIRP are listed as below. Submit your manuscript to us via either submit@scirp.org or Online Submission Portal.
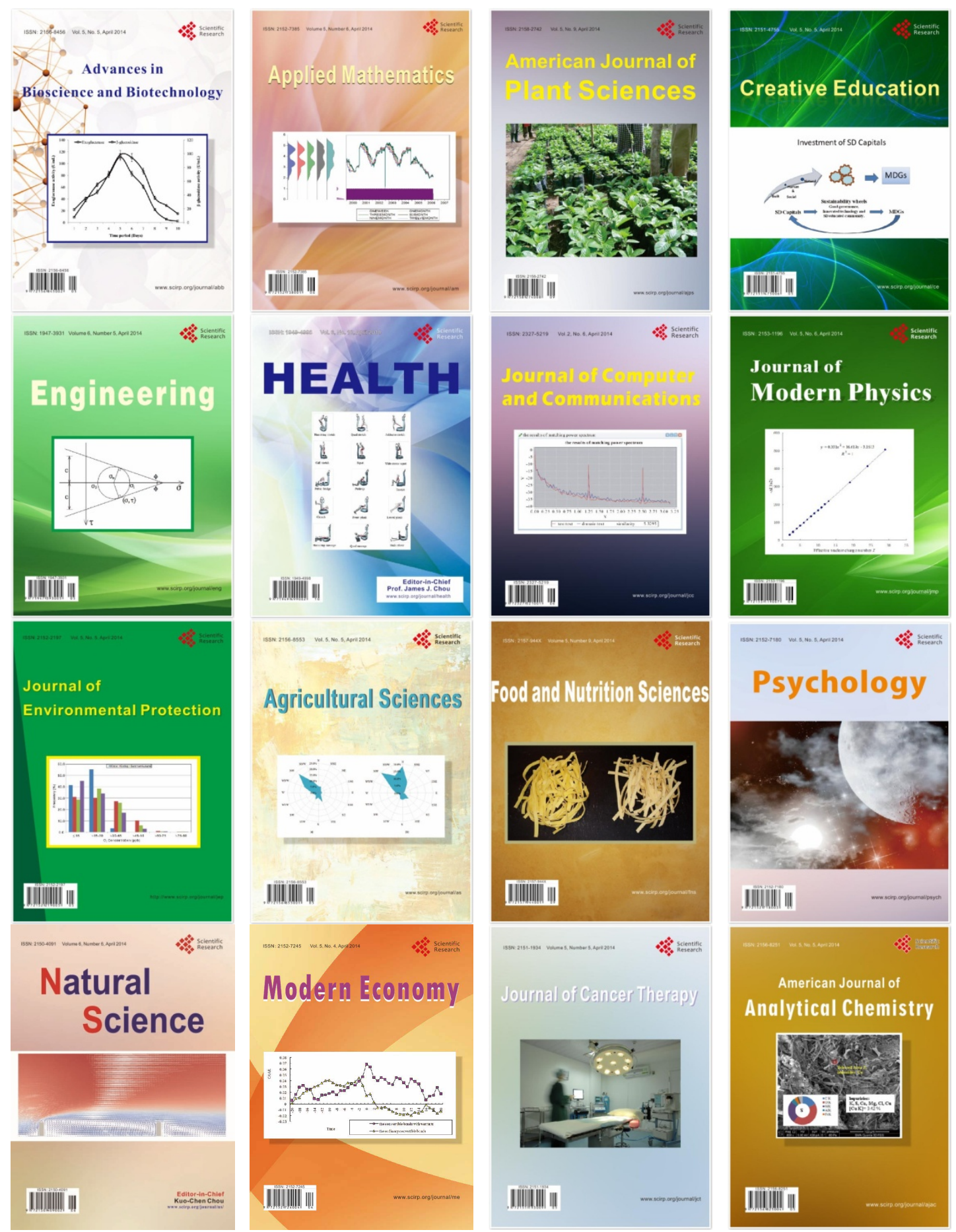